\title{
Expertise in Interpretation of 12-Lead Electrocardiograms of Staff and Residents Physician: Current Knowledge and Comparison between Two Different Teaching Methods
}

\section{Abstract}

Background and objectives: Electrocardiogram is a commonly used procedure for diagnosis of heart disease. It is not known doctor skills nowadays and utility of intensive course electrocardiogram teaching. The objective is to evaluate the accuracy in the interpretation of electrocardiograms among residents and staff doctor and evaluate the usefulness of an intensive training course in ECG (one week, 20 hours long) with a standard rotation in cardiology unit.

Methods: Participants were included prospectively and divided into two groups for analysis: Hospital Group (82 residents during their Cardiology rotation) and Course Group (71 residents and 41 staff physicians from the audience to a specific electrocardiogram course). They fill in 2 different questionnaires of 10 basic electrocardiograms: "Initial Test" at the beginning and "Final Test" at the end. We assign one point for each correct answer and zero for incorrect one (score range was 0 to 10 points).

Results: The score achieved in the "Initial Test" (standard deviation) was 5.09(1.81). Residents obtained 5.28(1.8), and Seniors 4.4(1.6), $\mathrm{p}=0.006$. In the "Final Test" score achieved was 5.91(1.9), Residents obtained 6.03(1.98) and staffs 5.48(1.7), $\mathrm{p}=0.104$. We found no differences in the "Final Test" score between both ECG teaching methods after adjusting.

Conclusion: Real ECG knowledge between doctors is poor. Residents obtained better results than staff at the beginning but at the end there were not statistic differences. Intensive course were similar to classical teaching method.

Keywords: Electrocardiography; Electrocardiography skills; Improving techniques; Teaching methods

\begin{tabular}{|c|}
\hline Research Article \\
\hline Volume 5 Issue 3 - 2016 \\
\hline $\begin{array}{l}\text { Javier Higueras }^{1 *} \text {, Sandra Gómez-Talavera }{ }^{2} \text {, } \\
\text { Victoria Cañadas }^{1} \text {, Ramón Bover }{ }^{1} \text {, Martínez- } \\
{\text { Losas } \mathrm{P}^{1} \text {, Juan Carlos Gómez-Polo }}^{1} \text {, Carmen } \\
\text { Olmos }^{1} \text {, Cristina Fernandez }{ }^{3} \text {, Julian } \\
\text { Villacastín }^{1} \text { and Carlos Macaya }\end{array}$ \\
\hline $\begin{array}{l}{ }^{1} \text { Department of Cardiology, Hospital Clinico Universitario San } \\
\text { Carlos, Spain }\end{array}$ \\
\hline${ }^{2}$ Department of Cardiology, Hospital de Fuenlabrada, Spain \\
\hline $\begin{array}{l}{ }^{3} \text { Department of Preventive Medicine, Hospital } \\
\text { ClínicoUniversitario San Carlos, Spain }\end{array}$ \\
\hline $\begin{array}{l}\text { *Corresponding author: Javier Higueras, Department } \\
\text { of Cardiology, Hospital Clínico Universitario San Carlos, } \\
\text { Profesor Martín Lagos SN, } 28040 \text { Madrid, Spain, Tel: 00-34- } \\
\text { 913303001; Email: javierhnb@yahoo.es }\end{array}$ \\
\hline ed: January 22, 2016 | Pub \\
\hline
\end{tabular}

Abbreviations: ECG: Electrocardiogram; AMI: Acute Myocardial Infarction; VT: Ventricular Tachycardia; LVH: Left Ventricular Hypertrophy; WPW: Wolff-Parkinson-White Pattern; IT: Initial Test; FT: Final Test; SD: Standard Deviation

\section{Introduction}

In 21st century, Electrocardiography is the most commonly used procedure for diagnosis of heart disease. It is frequently performed by many kinds of doctors. This procedure is simple, safe, reproducible, and relatively economical [1].

The 12-lead electrocardiogram (ECG) has numerous potential clinical uses. It serves as the first diagnostic step, and usually the main tool and sometimes the one and only in order to initiate treatment in arrhythmias, myocardial infarction, conduction abnormality, and in general, suspecting the presence of heart disease [2-7].
It is important for physicians of any specialty to whom have sufficient knowledge to make an accurate diagnosis. However, many doctors are unaware of their limitations and believe that they can interpret ECGs well [1]. Adequate knowledge should include the ability to define, recognize, and understand the basic pathophysiology of certain electrocardiographic abnormalities or patterns [2].

Very little is known about ECG interpretative skills of medical residents $[8,9]$. Accordingly, this study was designed to analyse the accuracy in the interpretation of a variety of basic ECGs among residents of several specialities and family staff doctors. We also wanted to test two different ways of teaching electrocardiography: a general rotation at the cardiology unit (not electrocardiography specific) and an electrocardiography one-week 20 hours long intensive course. A secondary goal was to identify particular weaknesses in ECG interpretation. interpretation of ECGs contributes to clinical decision-making to 


\section{Materials and Methods}

We collected data from June 2010 to January 2014.

\section{Participants}

Participants were included prospectively and divided into two groups for analysis:

a. Hospital Group consisted on consecutive eighty-two residents from different specialities that were recruited during their fellow at the Cardiology unit in a cardiovascular reference hospi- tal. Only one resident declined participation.

b. Course Group included seventy-one residents from different specialities and forty-two staff physicians $(n=113)$ from several hospital and healt care facilities recluted from the audience to a specific ECG course (one week, 20 hours long) that take place in the same hospital. All participants in this course consented to participate in this study.

The basal characteristics are summarised in Table 1. Participants' flow chart is showed in Figure 1.

Table 1: Basal characteristics of total population and different groups.

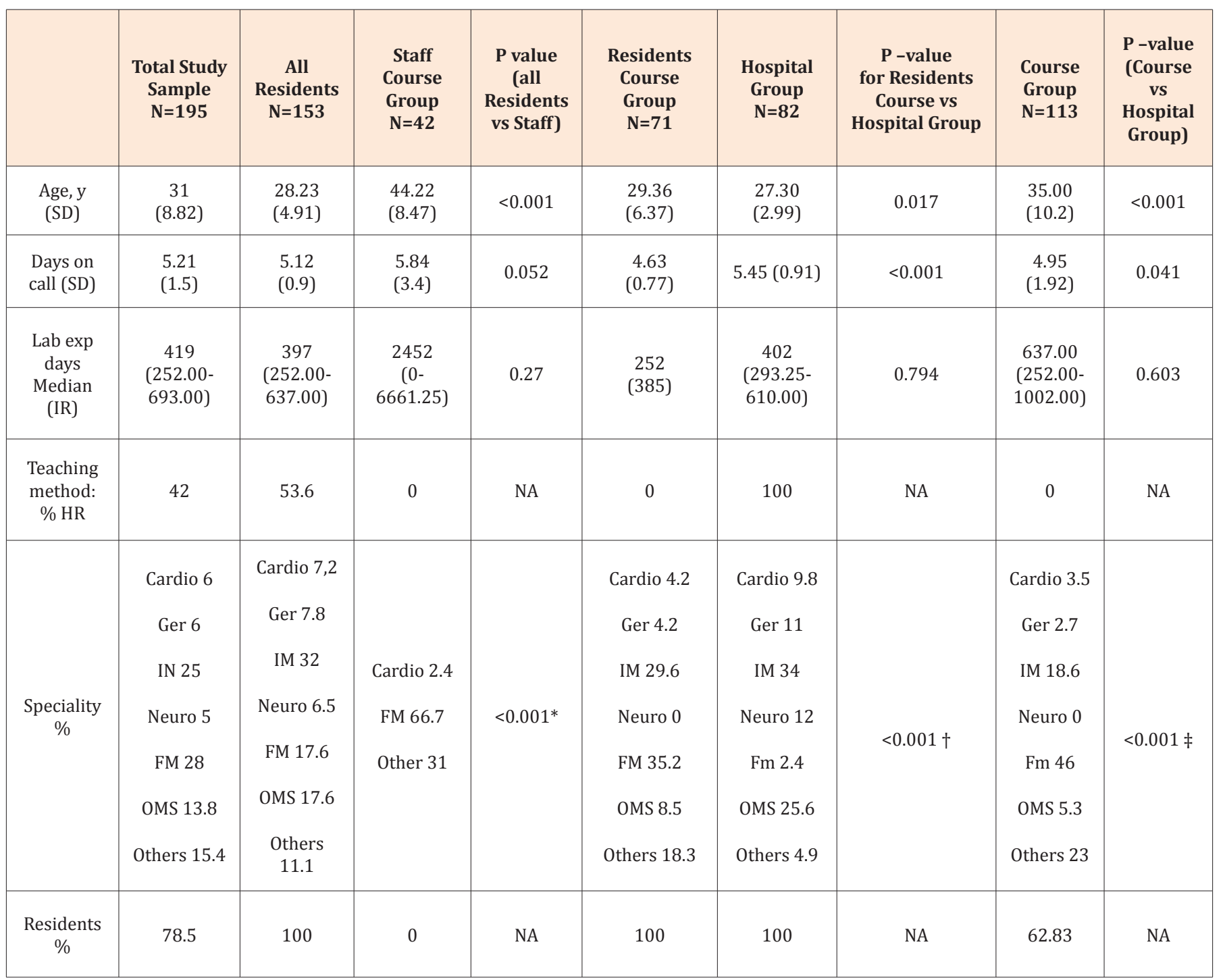

Cardio: Cardiology; FM: Family; Ger: Geriatry; HR: Hospital Rotation; IM: Internal Medicine; IR: Interquartile Range; ISD: Standard Deviation; LA: Latin America; Lab Exp: Lab Experience; NA: Not Applicable; Neuro: Neurology; OMS: Other Medical Speciality (anaesthesia, endocrinology, intensive care, nephrology, pulmonology); y: years.

Statistic significances with Family doctors and Others. †Statistic significances with Family doctors and Others and Other Medical Speciality $\ddagger$ Statistic significances with Family doctors and Others and Other Medical Speciality. 


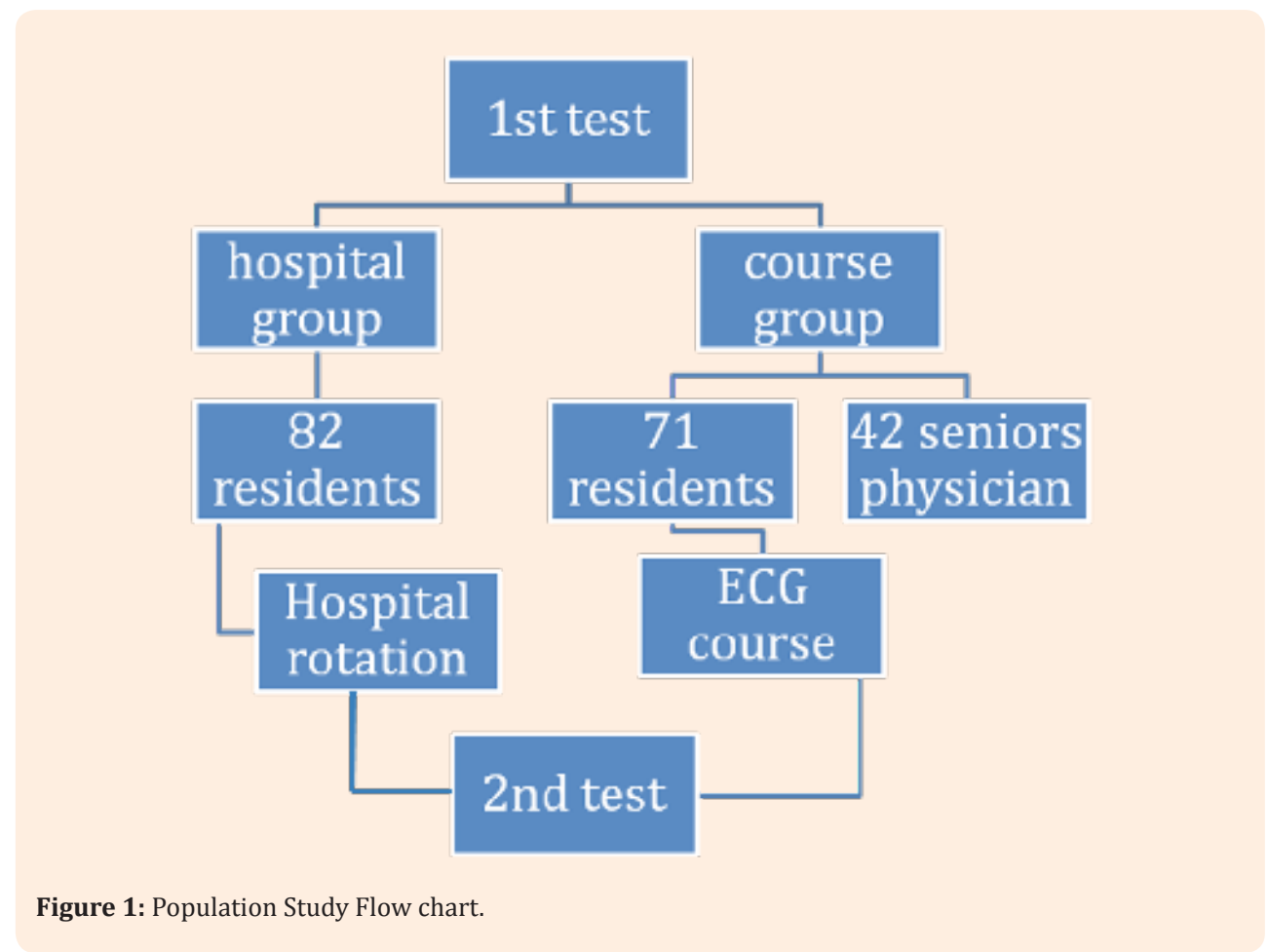

\section{Study design}

This study is a questionnaire-based assessment of physician's ability to interpret ECGs. Twenty 12-lead ECGs were selected from a cardiology database. The chosen ECGs were straightforward examples. Two senior cardiologists reviewed all ECGs independently and were asked to give a single diagnosis for each trace. They remained blinded to any clinical information or previous ECGs from the patient. There was $100 \%$ agreement on the diagnoses by the 2 experts.

The 20 ECGs represented examples of conditions that any noncardiologist physician should be able to diagnose. They included cases of acute myocardial infarction (AMI), atrial flutter with and without AV block, atrial fibrillation, ventricular tachycardia (VT), acute pericarditis, left ventricular hypertrophy (LVH), WolffParkinson-White pattern (WPW), type 2:1 second-degree AV block, complete heart block and cardiac tamponade. Some ECGs were obtained at the emergency department and specifically chosen because they illustrated urgent conditions that require immediate and accurate interpretation (i.e. AMI, VT, cardiac tamponade and complete heart block). The selected ECGs were divided into two sets to design two different questionnaires. One of them was called "Initial Test" (IT) and was administered to the participants before any teaching period (either rotation or course). After completion of the teaching period, a second one called "Final Test" (FT) was given to all participants. Table 2 lists the diagnoses of the 20 ECGs used in the study in the order they appeared in the questionnaires.
The questionnaires had a fill-in-the-blank format, and the participants were asked to interpret each ECG and describe their answer on a blank line on a separate answer sheet. None of the ECGs offered multiple-choice answers. All subjects were asked to complete both questionnaires without any prior knowledge of the study. No clinical history was provided and automatic interpretation of ECG machine was removed to avoid influencing the participant's interpretation of the ECG.

A score ranging from 0 (incorrect) to 1 (correct) was assigned to each ECG. If the primary diagnosis was given, the ECG was scored as correct and was granted 1 point. If the participant was unable to give the primary diagnosis, the ECG was scored incorrect and given a zero. All questions left unanswered were scored also zero. Thus, the maximum total score achievable for 10 correctly answered ECGs was 10 each test (Initial and Final Test).

We also collected the following information from each participant: age, days since the beginning of professional activity, speciality, birthplace, and the number of days on call on a normal month.

\section{Written informed consent was waived.}

\section{Statistical Analysis}

Two blinded, independent graders (J.H. and S.G.) revised and scored each participant's test. The analyses included both an investigation of physician interpretation of each individual ECG and the combination of the results of the 10 ECGs for an overall maximum achievable score of 10 in the Initial and Final Test. 
Table 2: Diagnosis of the two ECG questionnaires used in this study.

\begin{tabular}{|c|c|}
\hline \multicolumn{2}{|c|}{ ECG Diagnosis } \\
\hline IT1: Common Atrial Flutter with AV block & FT1: Common Atrial Flutter \\
\hline IT2: Ventricular Tachycardia & FT2: Ventricular Tachycardia \\
\hline IT3: Atrial Fibrillation & FT3: Atrial Fibrillation \\
\hline IT4: WPW pattern & FT4: WPW Pattern \\
\hline IT5: 2:1 2 ${ }^{\text {nd }}$ degree AV Block & FT6: Cardiac Tamponade ECG \\
\hline IT6: Normally functioning pacemaker ECG & FT7: Pacemarker dysfunction ECG (capture and sensing) \\
\hline IT7: Inferior Myocardial infarction & FT8: Normal pace marker ECG \\
\hline IT8: Cardiac Tamponade ECG & FT9: Pericarditis \\
\hline IT 9: Left Ventricular hypertrophy & FT10: Anterior Acute Myocardial Infarction \\
\hline IT10: Ventricular extrasystoles &
\end{tabular}

AV: Atrial-Ventricular; ECG: Electrocardiogram; FT: Final Test; IT: Initial Test; WPW: Wolf Parkinson White.

Quantitative data are presented as mean \pm standard deviation (SD) or median and interquartile range (p25-p75) in asymmetric ones. Qualitative variables are displayed with frequencies distribution and percentages.

A $\chi^{2}$ test or Fisher exact test (if $25 \%$ of expected were lower than 5 in independences samples) was used for qualitative variables. In paired data Mc Nemar's test was used. For the analysis of the ECG diagnosis accuracy and the differences between staffs and residents odds ratio and its confidence interval 95\% (CI 95\%) was obtained. We analysed quantitative variables for each of the independent variables categorized by the $T$ test Student (in comparisons of a variable with two categories) and/or analysis of variance (ANOVA). If asymmetry differences with non-parametric test, the Mann-Whitney test or the median test assessed where appropriate. In pair comparisons data corresponding test were used.

To set the final scores based on baseline scores and those potentially confounding factors multivariable linear regressions were modelled and the parameters are presented along with their CI $95 \%$.

In all hypothesis tests the null hypothesis with a type I error less than 0.05 or $\alpha$ error was rejected. The software package used for analysis was SPSS for Windows versión 15.0.

\section{Results}

\section{Total population}

The study sample consisted on 195 physicians (153 residents and 42 staff). They were 31 (SD 8.82) years old, with a lab experience of 419 days (RI: 252-693). The overall mean (SD) score achieved in the Initial Test was 5.09 (1.81) out of a maximum of 10 . The $50^{\text {th }}$ percentile was 5 points and $90^{\text {th }}$ percentile was 8 points. Residents obtained 5.28 [CI 95\% 4.98-5.57], and Seniors 4.4 [CI 95\% 3.90-4.91, p=0.006].

In the FT the overall mean (SD) score achieved was 5.91(1.9), representing an improvement in score of 0.8 points [CI 95\%
$0.55-1.12 ; \mathrm{P}<0.001]$. The $50^{\text {th }}$ percentile was 6 points and $90^{\text {th }}$ percentile was 8 points. Residents obtained 6.03 (1.98) and staffs 5.48 (1.7), $\mathrm{p}=0.104$. Almost $56 \%$ of residents improved their score (FT - IT $>0$ ), whereas $57 \%$ of staffs improved their score. The mean improvement in score was 0.75 points [CI 95\%, 0.44$1.10, \mathrm{p}<0.001$ ] for residents and1.07 [CI 95\% 0.47-1.67, $\mathrm{p}=0.001$ ] for staffs.

There were no differences in the FT score between residents and staffs, after adjusting by IT score, age and specialty. Differences between residents and staff are summarised in Table 3 .

\section{Comparison between hospital rotation and ECG course}

To compare the two different ECG teaching methods, we analysed only residents' results in order to achieve population homogeneity. The basal characteristics are summarised in Table 1.

In the IT, the mean score (SD) was 5.9 (1.80) for Hospital Group and 4.54 (1.57) for the residents in the Course Group $(\mathrm{p}<0.001)$. In the FT, Hospital Group achieved a mean score of 6.52 (2.01), whereas residents in Course Group obtained a mean score of 5.45 (1.80), ( $\mathrm{p}=0.001)$. Fifty six percent of residents in Hospital Group and $55.7 \%$ of residents in Course Group improved their score $(p=0.962)$. After their rotation, residents of Hospital Group improved 0.62points [CI 95\% 0.14-1.1; $\mathrm{p}=0.011$ ), while residents of Course Group improved 0.91 [CI 95\% (0.48-1.41) p<0.001]. We found no differences in the FT score between both methods after adjusting by IT score, speciality and age. There was statistically significant interaction between teaching method and speciality $(\mathrm{p}=0.003)$ Figure 2.

\section{ECG interpretation scores}

Table 4 lists the percentages of correct diagnoses obtained for each individual ECG. We show staff and residents results of total sample.

The most commonly reported incorrect response was 2:1 second degree $\mathrm{AV}$ block in staff group (only $4.8 \%$ of correct 
diagnoses) and LVH in residents group $(11.8 \%$ of correct diagnoses).Others ECGs with poor results $(<50 \%$ of correct diagnoses) in staff group were LVH (16.7\%), Cardiac Tamponade (21.4\% in Initial Test), WPW pattern (28.6\% in IT and $16.7 \%$ in FT), pericarditis $(16,7 \%)$, normally functioning pacemaker ECG (28.6\% in IT and $45.2 \%$ in FT), common Atrial Flutter (31\%) and VT (47.6\%). In residents group poor results were found in cardiac tamponade (23.5\% in IT), WPW syndrome $(29.4 \%$ in IT and $24,2 \%$ in FT) and pericarditis (37.3\%).

When analysing the ECGs with the most critical diagnoses, results were slightly better. On one hand, staff group did not achieve $50 \%$ of correct diagnoses in VT (47.6\%, in IT), type 2:1 $2^{\text {nd }}$ degree AV Block (4.8\%) and cardiac tamponade (21.4\% in IT). On the other hand, resident group did not achieve $50 \%$ of correct diagnoses in type 2:1 $2^{\text {nd }}$ degree AV Block (36.6\%). In FT, both staff and residents achieved almost 50\% of correct diagnostic in critical diseases (Table 5).

Table 3: Total residents score vs Staffs score.

\begin{tabular}{|c|c|c|c|}
\hline & $\begin{array}{c}\text { Residents Score (CI 95\%) } \\
\text { N:153 }\end{array}$ & $\begin{array}{c}\text { Staffs Score } \\
\text { (CI 95\%) } \\
\text { N:42 }\end{array}$ & P- Value \\
\hline ITS & $5.28(4.98-5.57)$ & $4.40(3.90-4.91)$ & 0.006 \\
\hline FTS & $6,03(5.71-6.34)$ & $5.48(4.94-6.01)$ & 0.104 \\
\hline Improvement (FTS-ITS) & $0.75(0.44-1.10)$ & $1.07(0.47-1.67)$ & 0.344 \\
\hline FTS Adjusted by ITS & $5.97(5.68-6.25)$ & $5.77(5.22-6.32)$ & 0.538 \\
\hline $\begin{array}{c}\text { FTS Adjusted by ITS and } \\
\text { speciality }\end{array}$ & $6.13(5.82-6.43)$ & $5.82(4.68-6.95)$ & 0.603 \\
\hline $\begin{array}{c}\text { FTS Adjusted by ITS, speciality } \\
\text { and age }\end{array}$ & $5.95(5.61-6.30)$ & $6.19(5.02-7.36)$ & 0.718 \\
\hline
\end{tabular}

CI: Confidence Interval; FTS: Final Test Score; ITS: Initial Test Score.

Table 4: Residents Hospital Group score vs Residents Course Group score.

\begin{tabular}{|c|c|c|c|}
\hline & $\begin{array}{c}\text { Residents Hospital } \\
\text { Group } \\
\text { (CI 95\%) } \\
\mathbf{~ N : 8 2}\end{array}$ & $\begin{array}{c}\text { Residents Course Group } \\
\text { (CI 95\%) } \\
\text { N:71 }\end{array}$ & P-Value \\
\hline ITS & $5.90[5.51-6.30]$ & $4.54[4.17-4.92]$ & $<0.001$ \\
\hline FTS & $6.52[6.08-6.97]$ & $5.45[5.02-5.88]$ & 0.001 \\
\hline Improvement (FTS-ITS) & $0.62(0.14-1.10]$ & $0.91(0.48-1.41)$ & 0.494 \\
\hline Adjusted by ITS & $6.28(5.87-6.69)$ & $5.77(5.33-6.22)$ & 0.112 \\
\hline Adjusted by ITS and speciality & $5.82(5.31-6.32)$ & $5,97(5.43-6.50)$ & 0.697 \\
\hline $\begin{array}{c}\text { Adjusted by ITS, speciality and } \\
\text { age }\end{array}$ & $5.80(5.29-6.31)$ & $5.93(5.38-6.48)$ & 0.733 \\
\hline
\end{tabular}

Confidence Interval; FTS: Final Test Score; ITS: Initial test score.

Citation: Higueras J, Gómez-Talavera S, Cañadas V, Bover R, Losas M et al. (2016) Expertise in Interpretation of 12-Lead Electrocardiograms of Staff and Residents Physician: Current Knowledge and Comparison between Two Different Teaching Methods. J Cardiol Curr Res 5(3): 00160. D0I: 10.15406/ jccr.2016.05.00160 
Table 5: ECG interpretation scores.

\begin{tabular}{|c|c|c|c|c|c|c|c|c|c|}
\hline ECG & $\begin{array}{c}\text { Staffs } \\
\%(\mathrm{~N}: 42)\end{array}$ & $\begin{array}{l}\text { Residents } \\
\% \text { (N:153) }\end{array}$ & P-value & $\begin{array}{c}\text { Odds Ratio } \\
\text { Resident/ } \\
\text { Staff }\end{array}$ & ECG & $\begin{array}{c}\text { Seniors } \\
\%(\mathrm{~N}: 42)\end{array}$ & $\begin{array}{l}\text { Residents } \\
\% \text { (N:153) }\end{array}$ & P-value & $\begin{array}{c}\text { Odds Ratio } \\
\text { Resident/ } \\
\text { Staff }\end{array}$ \\
\hline $\begin{array}{l}\text { IT1: CAF } \\
\text { with AVB }\end{array}$ & $90.5(38)$ & $\begin{array}{l}88.95 \\
(136)\end{array}$ & $>0.999$ & $\begin{array}{c}0.84[0.27- \\
2.65]\end{array}$ & FT1: CAF & $31.0(13)$ & $52.9(81)$ & 0.012 & $\begin{array}{c}2.51 \text { [1.21- } \\
5.19]\end{array}$ \\
\hline IT2: VT & $47.6(20)$ & $61.4(94)$ & 0.091 & $\begin{array}{c}1.80 \text { [0.91- } \\
3.58]\end{array}$ & FT2: VT & 66.7 (28) & $58.2(89)$ & 0.319 & $\begin{array}{c}0.69[0.34- \\
1.42]\end{array}$ \\
\hline IT3: AF & 69.0 (29) & $72.0(110)$ & 0,655 & $\begin{array}{c}1.18 \text { [0.56- } \\
2.49]\end{array}$ & FT3: AF & 81.0 & 92.8 & 0.036 & $\begin{array}{c}3.04[1.13- \\
8.13]\end{array}$ \\
\hline $\begin{array}{c}\text { IT4: WPW } \\
\text { Pattern }\end{array}$ & $28.6(12)$ & $29.4(45)$ & 0.916 & $\begin{array}{c}1.04[0.490- \\
2.21]\end{array}$ & $\begin{array}{c}\text { FT4: WPW } \\
\text { Pattern }\end{array}$ & 16.7 (7) & $24.2((37)$ & 0.302 & $\begin{array}{c}1.59[0.65- \\
3.89]\end{array}$ \\
\hline $\begin{array}{c}\text { IT5: type } \\
\text { 2:1 } 2^{\text {nd }} \\
\text { degree AVB }\end{array}$ & $4.8(2)$ & $36.6(56)$ & $<0.001$ & $\begin{array}{c}11.545[2.69- \\
49.60]\end{array}$ & $\begin{array}{c}\text { FT5: Complete } \\
\text { AVB }\end{array}$ & 92.9 (39) & $82.4(126)$ & 0.095 & $\begin{array}{c}0.36[0.10- \\
1.25]\end{array}$ \\
\hline $\begin{array}{c}\text { IT6: Normal } \\
\text { PM }\end{array}$ & 28.6 & 56.9 (87) & 0.001 & $\begin{array}{c}3.29 \text { [1.57- } \\
6.92]\end{array}$ & $\begin{array}{c}\text { FT6: Cardiac } \\
\text { Tamponade } \\
\text { ECG }\end{array}$ & $83.3(35)$ & 71.2 (109) & 0.114 & $\begin{array}{c}0.49[0.20- \\
1.20]\end{array}$ \\
\hline $\begin{array}{l}\text { IT7: Inferior } \\
\text { wall AMI }\end{array}$ & 90.5 & 87.6 (134) & 0.789 & $\begin{array}{c}0.74[0.24- \\
2.31]\end{array}$ & $\begin{array}{c}\text { FT7: PM } \\
\text { dysfunction } \\
\text { (capture and } \\
\text { sensitivity) }\end{array}$ & $50(21)$ & $55.6(85)$ & 0.601 & $\begin{array}{c}0.74[0.24- \\
2.31]\end{array}$ \\
\hline $\begin{array}{c}\text { IT8: Cardiac } \\
\text { Tamponade } \\
\text { ECG }\end{array}$ & 21.4 (9) & $23.5(36)$ & 0.775 & $\begin{array}{c}1.129[0.49- \\
2.58]\end{array}$ & $\begin{array}{c}\text { FT8: Normal } \\
\text { PM }\end{array}$ & 45.2 (19) & $60.8(93)$ & 0.08 & $\begin{array}{c}1.13[0.50- \\
2.58]\end{array}$ \\
\hline IT 9: LVH & $16.7(7)$ & 11.8 (18) & 0.43 & $\begin{array}{c}0.67[0.26- \\
1.72]\end{array}$ & $\begin{array}{c}\text { FT9: } \\
\text { Pericarditis }\end{array}$ & 16.7 (7) & 37.3 (57) & 0.015 & $\begin{array}{c}2.97[1.24- \\
7.12]\end{array}$ \\
\hline IT10: VE & $42.9(18)$ & $54.9(84)$ & 0.22 & $\begin{array}{c}1.623[0.81- \\
3.23]\end{array}$ & $\begin{array}{c}\text { FT10: } \\
\text { Anterior wall } \\
\text { AMI }\end{array}$ & $64.3(27)$ & 70.6 (108) & 0.433 & $\begin{array}{c}1.33[0.65- \\
2.74]\end{array}$ \\
\hline
\end{tabular}

AF: Atrial Fibrillation; AMI: Acute Myocardial Infarction; AVB: Atrial-Ventricular Block; CAF: Common Atrial Flutter; ECG: Electrocardiogram; FT: Final Test; IT: Initial Test; LVH: Left Ventricular Hypertrophy; PM: Pacemaker; VE: Ventricular Extrasystoles; VT: Ventricular Tachycardia; WPW: WolfParkinson-White.

\section{Discussion}

\section{ECG interpretation skills}

In this study the overall accuracy of ECG interpretation was low for both resident and staff physicians. This finding is of particular interest given the fact that the ECGs were chosen as examples of diseases or conditions that any physician should have been able to recognize and properly diagnose.

In the present work residents score was 5.28 in IT and 6.03 in FT. A systematic review published in 2003 that included 12 articles, demonstrated that resident physicians detected 36\% to $80 \%$ of ECG diagnoses as determined by experts [10]. Our results are consistent with these findings. Few studies have investigated ECG interpretation skills of resident physicians. Commonest errors reported in the literature are failure to recognize AV block, acute posterior MI, and supra ventricular dysrhythmia [11]. In the present study, AMI was missed by $13.4 \%$, VT was missed by $44.1 \%$, and $2^{\text {nd }}$ degree AV block was missed by $64.6 \%$ of the residents in the IT. In a study by Gillespie et al. [12] more than $50 \%$ of residents failed to recognize AV block and posterior MI when interpreting ECGs. It is notable that although residents improved their results, the score of FT remained poor. We expected residents to have achieved higher scores after the teaching period.

The study also revealed that staffs' competency was even poorer. This group was composed of $66 \%$ family doctors and $33 \%$ general practitioners and out-hospital emergency physicians. They obtained 4.4 points in IT and 5.4 points in FT, improving on average 1 point at the end of the ECG course. There are few available data of ECG interpretation skills of staff physicians. In a recent Swiss study, the mean proportion of correct answers was only $31 \%$ [13]. Other studies show similar findings. Accurate ECG diagnoses were observed in only $36 \%$ of senior house officers and in $17 \%$ to $67 \%$ of family doctors [14]. More important, there were a significant proportion of potentially fatal diseases that were missed: less than $50 \%$ of doctors were able to correctly detect VT, $2^{\text {nd }}$ degree AV block or cardiac tamponade. 
It is remarkable that Residents Group obtained better score in IT than Staffs, but in FT there were not differences, perhaps indicating a better utilization of teaching method by the staffs.

Many causes could be responsible of these poor results. No clinical information or automatic interpretation of ECG machine was provided to avoid influencing the participant's interpretation of the ECG. Previous research has demonstrated a strong and consistent effect of clinical scenario on the accuracy of ECG interpretation and identification of ECG features by physicians at all levels of training, but especially for providers with less experience [9,15-17]. Moreover, non-cardiologists seem to be more affected by the clinical context of the patient when interpreting an ECG [15]. Otherwise pattern recognition, which is an essential component of ECG interpretation, is learned only through repeated exposure. Such repeated exposure is especially important because of the need to visually recognize the many diagnostic variations. It is known that completion of a residency or fellowship does not guarantee adequate training in electrocardiography [18]. Although there is no scientific study to rely on, it is estimated that most physicians can obtain competence only after reading at least 500 tracings under the supervision of an expert electro-cardiographer [2]. Perhaps, in the era of a highly technological medicine, physicians are more prone to base their judgement on imaging techniques such as echocardiography, scanner and cardiac resonance than in classic diagnostic tools like ECG, chest radiograph or even physical examination. As a consequence, they may not recognize the value of acquiring and maintaining competency in ECG interpretation. In the worst side, this is the real ECG knowledge of physician in our days $[14,15,19,20]$.

\section{Assessment of the teaching methodologies}

Both ECG teaching methods seem to have helped residents to improve their ability to accurately interpret ECGs. Residents in Hospital group completed a cardiology rotation with a median duration of 77.5 days (IR 33). They improved on average 0.62 points, whereas residents in the course group improved 0.91 points. When comparing the FT score, we found no statistically significant differences between these two teaching methods, neither in the univariate nor in the multivariate analysis. Analysing FT score, univariate analysis and after adjusted by Initial Test score, age and speciality there were not significant differences between both learning methods.

There are many teaching methodologies that have demonstrated their utility: traditional instruction and ECG puzzle methods [21] self-directed learning, specific workshops or lectures [22]. In these studies, diagnostic accuracy improved 10\% to $15 \%$ with any of the teaching methods, which is consistent with our results. In our study, residents in the course group improved their score $9.1 \%$ those in the hospital group, $6.2 \%$. So, specific one-week course seems to be as effective of those ECG learning methods.

\section{Specific weaknesses in ECG interpretation}

Staff group (66\% family doctors, 33\% others) obtained poor scores in some cardiac conditions or disease like, as WPW pattern, hypertrophic cardiomyopathy, pacemaker's ECG or cardiac tamponade. This finding is probably related to the fact these conditions are not frequently seen in their daily practice. Consequently, they got better results in those ECGs, like atrial fibrillation or atrial flutter that are frequent in a general practitioner's office.

Myocardial infarction was correctly identified by most of the staffs (90.5\%), being one of the conditions with the best results. This is consistent with other studies and probably due to the high prevalence of ischemic heart disease in our days and the capital role of family doctors and out-hospital emergency doctors play in diagnostic and therapeutic chain of the ischemic process [10].

Resident group (28.23 years, 397 days of lab experience on average) obtained poorest scores in the same specific diseases (WPW pattern, type 2:1 $2^{\text {nd }}$ degree AV Block, cardiac tamponade, myocardial hypertrophic disease). In this group, the results could be better explained by the lack of experience. They had also the best results in myocardial infarction, probably because they were familiar with such a frequent condition nowadays.

Both groups obtained poor results in some potentially fatal diseases. However residents obtained better scores than staff in type 2:1 $2^{\text {nd }}$ degree AV Block (4.8 vs $36.6, p<0.001$ ), VT (47.6 vs $61.4 \% \mathrm{p}=0.091$ ), pericarditis ( 16.7 vs $37.3, \mathrm{p}=0.015$ ) and normally functioning pacemaker ECG (IT: $28.6 \%$ vs $56.9 \%$, p=0.001, FT: $45.2 \%$ vs $60.8 \%$, $\mathrm{p}=0.08$ ).

The present study highlights that the current electrocardiography knowledge is undoubtedly poor. Many reasons can be argued: a lack of practical experience, the inadequacy of residency teaching programs to reach a proper competency, the failure of continuing medical education or the devaluation of this classic diagnostic tool in favour of the other techniques. Nevertheless, we found that both teaching methods can be useful in improving ECG interpretation skills in both residents and staffs.

In view of our results we consider that improving teaching methodology is of great importance, not only to give residents the opportunity of obtain proper ECG interpretation skills but also to guarantee that they, as staffs, are able to maintain a good level of competency in this field. Efforts should be intensified in those conditions that are usually missed by non-cardiologists. New technologies can help us to design new attractive and teaching tools such as online courses, online contest or specific periodic evaluation format.

\section{Limitations}

This study has many limitations that deserve consideration. First, it is not a randomised study and groups are not necessarily comparable. Although we have adjusted our results by the most frequent confounding factors, we cannot exclude the existence of biases. On the other hand, the 2 ECG questionnaires are not standardised. We have chosen 20 easy and frequent ECG and divided them into two homogeneous groups. But it is possible than one of them could be more difficult. Finally, this is a small single-center study, and therefore it is not representative of the nation as a whole. 


\section{Conclusion}

Young residents of several specialities and general staff physician demonstrated overall low proficiency when interpreting daily practice ECGs.

ECG specific course and cardiology rotation have demonstrated to be useful improving ECG knowledge. Nevertheless, we should find new methods in order to achieve better results. There was an statistically significant interaction between teaching method and speciality. Familiy doctors improve FT score better with course method than hospital one.

\section{Authors Contributor ship}

Higueras J contributed in study design, patient inclusion, ECG analysis, data analysis and the process of article writing. He is the responsible for the overall content as guarantor.

Gómez-Talavera S contributed in patient inclusion and ECG analysis of every participant and data analysis.

Cañadas V contributed in data analysis and the process of article writing.

Martínez-Losas P, contributed in patient inclusion and the process of article writing.

Bover R contributed in patient inclusion and data analysis. sion.

Gómez-Polo JC contributed in study design and patient inclu-

Olmos C, contributed in study design and patient inclusion.

Fernandez C contributed in study design, data analysis and statistical analysis.

Villacastín J contributed in study design and patient inclusion.

Macaya C contribute in study design, data analysis.

\section{References}

1. Hurst JW (2006) The interpretation of electrocardiograms: pretense or well- developed skill? Cardiol Clin 24(3): 305-307.

2. Kadish AH, Buxton AE, Kennedy HL, Knight BP, Mason JW, et al. (2001) ACC/AHA clinical competence statement on electrocardiography and ambulatory electro-cardiography. Circulation 104(25): 3169-3178.

3. Steg PG, James SK, Atar D, Badano LP, Blömstrom-Lundqvist C, et al. (2012) ESC Guidelines for the management of acute myocardial infarction in patients presenting with ST-segment elevation. Eur Heart J 33(20): 2569-2619.

4. Brignole $\mathrm{M}$, Auricchio A, Esquivias BG, Bordachar P, Boriani G, et al. (2013) 2013 ESC guidelines on cardiac pacing and cardiac resynchronization therapy: the task force on cardiac pacing and resynchronization therapy of the European Society of Cardiology (ESC) Developed in collaboration with the European Heart Rhythm Association (EHRA). Europace 15(8): 1070-1118.

5. Thygesen K, Alpert JS, Jaffe AS, Simoons ML, Chaitman BR, et al. (2012) Third universal definition of myocardial infarction. Eur Heart J 33(20): 2551-2567.

6. Zipes DP, Camm AJ, Borggrefe $\mathrm{M}$, Buxton AE, Chaitman B, et al. (2006) ACC/AHA/ESC 2006 guidelines for management of patients with ventricular arrhythmias and the prevention of sudden cardiac death: a report of the American College of Cardiology/American Heart Association Task Force and the European Society of Cardiology Committee for Practice Guidelines. Europace 8: 746-837

7. Borrás X, Murga N, Fiol M, Pedreira M (2010) Novedades en cardiología clínica: electrocardiografía de superficie, enfermedad vascular y mujer y novedadesterapéuticas. Rev Esp Cardiol 63(Supl.1): 3-16.

8. Vergara C (2003) EKG rhythm interpretation patterns of medical interns: a need assessment test. Conn Med 67(2): 79-85.

9. Eslava D, Dhillon S, Berger J, Homel P, Bergmann S (2009) Interpretation of electrocardiograms by first-year residents: the need for change. Journal of electrocardiology 42(6): 693-697

10. Salerno SM, Alguire PC, Waxman HS (2003) Competency in interpretation of 12-lead electrocardiograms: a summary and appraisal of published evidence. Ann Intern Med 138(9): 751-160.

11. Trzeciak S, Erickson T, Bunney B, Sloan EP (2002) Variation in patient management based on ECG interpretation by emergency medicine and internal medicine residents. Am J Emerg Med 20(3): 188-195.

12. Gillespie ND, Brett CT, Morrison WG, Pringle SD (1996) Interpretation of the emergency electrocardiogram by junior hospital doctors. J AccidEmerg Med 13(6): 395-397.

13. Goodacre S, Webster A, Morris F (2001) Do computer generated ECG reports improve interpretation by accident and emergency senior house officers? Postgrad Med J 77(909): 455-457

14. Woolley D, Henck M, Luck J (1992) Comparison of electrocardiogram interpretations by family physicians, a computer, and a cardiology service. J Fam Pract 34(4): 428-432.

15. Hatala R, Norman GR, Brooks LR (1999) Impact of a clinical scenario on accuracy of electrocardiogram interpretation. J Gen Intern Med 14: 126-129.

16. Tsai TL, Fridsma DB, Gatti G (2003) Computer Decision Support as a Source of Interpretation Error: The Case of Electrocardiograms. J Am Med Inform Assoc 10(5): 478-483.

17. Martínez-Losas P, Higueras J, Gómez-Polo JC, Cañadas-Godoy V (2016) Influencia de la información clínica en la interpretación electrocardiográfica. Rev Clin Esp doi:10.1016/j.rce.2015.12.005.

18. Pinkerton RE, Francis CK, Ljungquist KA, Howe GW (1981) Electrocardiographic training in primary care residency programs. JAMA 246: 148-150.

19. Salerno SM, Alguire PC, Waxman HS (2003) Training and Competency in interpretation of 12-lead electrocardiograms: recommendations from the American College of Physicians. Ann Intern Med 138(9): 747-750.

20. Goy JJ, Schlaepfer J, Stauffer JC (2013) Competency in interpretation of 12-lead electrocardiogram among Swiss doctors. Swiss Med Wkly 143: w13806

21. Rubinstein, Dhoble A, Ferenchick G (2009) Puzzle based teaching versus traditional instruction in electrocardiogram interpretation for medical students- a pilot stydy. BMC Med Educ 9: 4

22. Mahler SA, Wolcott CJ, Swoboda Tk, Wang H, Arnold TC (2011) Techniques for teaching electrocardiogram interpretation: selfdirected learning is less effective than workshop or lecture. Med Educ 45(4): 347-353. 